\title{
Tractarian Sätze: Instructions for Use
}

\section{Jan Wawrzyniak ${ }^{1}$ (1)}

Received: 8 January 2019 /Revised: 24 May 2019 / Accepted: 21 August 2019/

Published online: 2 September 2019

(C) The Author(s) 2019

\begin{abstract}
The main question addressed by this article is this: How should one understand the role of the sentences of the Tractatus, given Wittgenstein's statement that they are nonsensical? I begin with a presentation of three general principles of interpretation in order to avoid answering the question in an inappropriate way. I then move on to a short presentation and commentary on a selection of readings - namely, the ineffabilist, resolute and elucidatory ones - and elaborate the answers given by advocates of these to the question explored here. I agree on many points with resolute and elucidatory readings: the Tractatus presents an austere conception of nonsense, and is not a book that seeks to present ontological or semantic theories. I point out, however, that these readings cannot fully explain the nature of Tractarian elucidations. Then I discuss those parts of the Tractatus which refer to the sentences of the book itself. The main proposal of my own approach is this: Tractarian elucidations should be construed as rules of translation (definitions), in that they show how to substitute certain expressions for others. They enable us to construct a notation in which everything that is expressible in ordinary language can be said perspicuously.
\end{abstract}

Keywords Interpretation of the Tractatus $\cdot$ Nonsense $\cdot$ Rule of translation $\cdot$ Philosophical proposition

\section{The Problem: The Status of the Sentences of the Tractatus}

Amongst commentators on the Tractatus Logico-Philosophicus (TLP) there exists a consensus about just two points: that it is no ordinary philosophical text, and that there is a huge variety of radically different interpretations of it. One of the main reasons for the latter is the controversy about the status of the sentences that make up the book.

Jan Wawrzyniak

jan.wawrzyniak@up.krakow.pl; janekwaw@poczta.fm

1 Institute of Philosophy and Sociology, Pedagogical University of Cracow, ul. Podchorążych 2, 30-084 Kraków, Poland 
This controversy has emerged from different readings of Wittgenstein's remarks on the nature of philosophy and the role that the Tractatus's sentences are supposed to play.

Wittgenstein, in 4.112, states that philosophy is an activity, and that a philosophical work consists of elucidations. He also adds that the result of philosophical activity is not a set of philosophical propositions. Hence the elucidations contained in the Tractatus are not - so it would seem - philosophical propositions. So what are they? What is their function? Indeed, the question of the status of the Tractatus's sentences turns out to be still more complicated, once one takes into account 6.54 :

6.54. My propositions [sentences] serve as elucidations in the following way: anyone who understands me eventually recognizes them as nonsensical, when he has used them - as steps - to climb up beyond them. (He must, so to speak, throw away the ladder after he has climbed up it.) He must transcend these propositions [sentences], and then he will see the world aright. (TLP 1961) ${ }^{1}$

The sentences of the Tractatus are described in the above quotation as nonsensical. Of course, this description gives rise almost immediately to the following questions: can anything be elucidated by nonsensical sentences and, if so, how is that possible?

So, the questions about the interpretation of the Tractatus with which I am concerned here can be summarized thus: given the supposition that they are not philosophical propositions, what philosophical role does the formulation of the Tractatus's sentences play, and how should the recognition of those sentences as nonsensical itself be characterized? Until now, both of these questions have received very different sorts of answer. While many of these contain remarks concerning the Tractatus's sentences that I would wholeheartedly approve of, I have yet to find a reading that strikes me as entirely convincing. For that reason, I would like to present my own interpretative framework. My aim in offering yet another overall approach to the interpretation of this work is to broaden, at least minimally, our perspective on the sentences of the Tractatus. The main idea to be presented is that the sentences of the Tractatus, in general, play the role of rules of translation. That is, they allow one to translate sentences formulated in one notation into sentences formulated in another. The translation serves to avoid confusions generated by mistaken interpretations of our statements. However, it should be added that after one has arrived at a definitive termination of the process of reading, one stops using the Tractatus's sentences, and when one stops using them, then they are recognized as nonsensical. I would like also to point out that although there are some similarities between my interpretation and Kuusela's (Kuusela 2012) interpretation, they differ in important respects, which I will touch on briefly in the Appendix.

Before presenting my conception in more detail, there are certain preliminary issues that I should like to address. Firstly, I wish to present the principles which, in my opinion, should guide the process of reading the Tractatus. Secondly, I shall outline the most popular interpretations of the role of the Tractatus's sentences, together with the

\footnotetext{
"I cite the 1961 McGuinness \& Pears translation here, as Ogden and Ramsey translate "unsinnig" into "senseless" rather than "nonsensical", which in my opinion is a mistake. I also think that in this context the German word "Satz" should be rendered in English as "sentence". Unless otherwise indicated, all other references to the Tractatus will be to the 1922 Ogden and Ramsey translation.
} 
main objections to these. Thirdly, I want to discuss those parts of the text of the book which directly or indirectly refer to its sentences.

\section{Principles of Interpretation}

That the content of a philosophical text imposes some constraints on its interpretation is, I think it is fair to say, a truism. Moreover, in my view it is possible to formulate some very general principles by which one should be guided while interpreting any such text. (Of course, this possibility does not mean that anyone who sticks to these principles will ultimately have to accept what emerges as the sole valid interpretation: the process of interpretation cannot be reduced to what follows from the mere application of a series of algorithms). My view is that such remarks hold good even where texts that are as highly specific and distinctive as the Tractatus are concerned. That is, it is possible to lay down a certain set of principles by which one should be guided while trying to understand even this book.

Firstly, a correct interpretation should try to take into account all parts of the given text. If a proposed reading of an entire text is not coherent in relation to a certain fragment of it, we have good reason to reject this interpretation. Such a reading may be accepted only in extraordinary circumstances. Moreover, it should only be accepted provisionally, until a more comprehensive interpretation (i.e. one taking into account more fragments of the text than did the previous one) can be formulated. Secondly, an interpretation ought to be coherent. Now one might question this principle, on the basis that some texts are not self-consistent, but I regard this objection as unconvincing, as the statement that a given text is incoherent is not itself incoherent: for example, the statement that there are two contradictory propositions in a given text is not a contradictory statement. Thirdly, we should construe a text in such a way as to render it maximally convincing and coherent. Of course, our reading should not be completely arbitrary: while interpreting it we take it for granted that the author is using words in an intelligible way - that is, in accordance with some received practice pertaining to their usage.

\section{An Overview of Interpretations}

At present, the most popular readings of the Tractatus are the ineffabilist, resolute and elucidatory interpretations. Of course, this list does not include all possible kinds of reading of the book, but I will confine myself to the presentation of these because, as I said, they are the ones currently dominant.

I shall begin with a discussion of the type of interpretation known by its critics as the "ineffabilist reading". According to this, the Tractatus is a book attempting to convey certain ineffable metaphysical truths by means of nonsensical sentences. ${ }^{2}$ (Anscombe 1965; Fogelin 1976; Geach 1976; Hacker 1986; Hacker 2000; Hacker 2003; Kenny

\footnotetext{
${ }^{2}$ In this context, the term "metaphysical truth" refers to every sentence which, according to its users, is used not only as a representation of necessary features of reality, but also as a representation of necessary features of, for example, thought or language.
} 
1973; Pears 1988; Stenius 1960; Stern 1995; White 2011). This reading assumes that although sentences such as " 1 . The world is everything that is the case", "2.033. The form is the possibility of the structure", "3. The logical picture of the facts is the thought", and "4.53. The general propositional form is a variable" (TLP) are nonsensical, they attempt to convey what manifests itself in the use of meaningful sentences and tautologies. So, this kind of interpretation assumes that there are at least two kinds of nonsense: mere nonsense, and nonsense construed as a means for conveying metaphysical truth. Moreover, the difference between these two kinds of nonsense is not just psychological: it is not simply that nonsensical sentences of the one kind seem meaningful to us, whereas sentences of the other seem devoid of any meaning. The difference, according to this interpretation, is that nonsensical sentences of the one kind are somehow connected with metaphysical truths, whereas those of the other kind are mere gibberish.

The main line of criticism directed at this kind of interpretation is the one initiated by Diamond (1991b) and Conant (1993). They have pointed out that proponents of this kind of interpretation fail to take 6.54 seriously, in that the latter are in effect claiming that the Sätze of the Tractatus somehow convey certain contents. At the same time, it is worth noting here that the relation between the Sätze of the Tractatus and the contents allegedly conveyed by them is not clear: adherents of the ineffabilist interpretation themselves deny that these Sätze express contents. Still, the fact that Wittgenstein himself does not distinguish between the two kinds of nonsense in the Tractatus arguably furnishes some sort of reason to abandon the ineffabilist line of interpretation (TLP 5.473, 5.4733 and 6.53; Conant 1993, 2000, 2002; Conant and Diamond 2004; Diamond 1991b, 2000, 2005; Goldfarb 1997). Moreover, the claim that certain nonsensical sentences somehow convey certain contents does just seem to boil down to the assertion that those sentences, when understood in a certain way, are in fact meaningful. This suffices to show that the conception of nonsense accepted by adherents of the ineffabilist reading is absurd (Witherspoon 2000). And further to this, there is yet another objection to the ineffabilist reading, closely connected to that just mentioned: namely, that this interpretation assumes that Wittgenstein based the conclusion that Tractarian sentences are nonsensical on certain metaphysical and semantic propositions (Hutto 2003: 88-90). If certain sentences are nonsensical, i.e. not given any definite meaning, they cannot be either the premises or the conclusions of any reasoning, since only tautologies, contradictions and meaningful sentences may serve as premises and conclusions. And so, according to this reading, the Sätze of the Tractatus should both be and not be nonsensical (Goldfarb 2011: 14). Taken together, I think it is fair to say that these objections make it clear that ineffable readings violate all of the principles of interpretation presented earlier.

Not only have Diamond and Conant criticized ineffabilist readings of the Tractatus, but they have also initiated an alternative approach to this text. Ricketts coined the term "resolute reading" for this - one that has since come to be accepted by commentators on the Tractatus. According to this kind of interpretation (supported also by other commentators: Floyd 2007; Goldfarb 1997, 2011; Kremer 2001; Ricketts 1996), the aim of the Tractatus is to lead the reader to recognize that philosophical theses are in fact sentences to which no definite sense has been given. Proponents of resolute readings claim that the difference between mere gibberish and sentences which allegedly express philosophical statements is purely psychological: the latter, in contrast to 
the former, seem to be meaningful, but there is no logical difference between sentences which allegedly express philosophical statements and mere nonsensical sentences, as both are strings of signs to which no sense has been ascribed. Wittgenstein - in contrast to what Hacker claims $(2000,2003)$ - does not hold that certain sentences are nonsensical because they violate the rules of logical syntax. According to him, nonsensical sentences do not consist of elements that have been given the wrong meaning, but rather of elements to which no meaning has been given. One may say that according to resolute interpretations, Wittgenstein is inviting his readers to enter into a certain sort of game: they start to wonder whether they are ready to give a definite sense to the sentences of the Tractatus, and reading the book leads them to recognize on the basis of ordinary criteria of meaningfulness (Diamond 2011: 272) - that its sentences are nonsensical. This recognition is piecemeal (Diamond 2004: 153-154); the claim that the sentences of the Tractatus are nonsensical is not inferred from any ineffable doctrines that are somehow supposedly conveyed by it (Conant and Bronzo 2017). The correct reading of the Tractatus leads to the removal of philosophical problems which stem from "the misunderstanding of the logic of our language." (TLP: Preface, cf. 4.003).

It should be noted, however, that there are important differences between different kinds of resolute reading (Bronzo 2012). I should like to consider just one such difference here. According to some adherents of the resolute approach, the sentences of the Tractatus can be divided into what are referred to as "the frame" and "the body". The sentences which the frame consists of instruct the reader how to interpret the book. One can ascribe a definite sense to these sentences. The book's Preface, and 6.54, are among others - often included in this. What the exact scope should be of the sentences assigned to the frame, and how these sentences are to be selected as such, are questions that remain controversial, even amongst the adherents of this conception. The frame is contrasted with the body, where the latter consists of philosophical elucidations eventually to be recognized as nonsensical. However, the division into frame and body has also come in for critical questioning by some adherents of the resolute approach, as itself manifesting a form of irresoluteness (Read and Deans 2011). What that amounts to is that reading the Tractatus should result in a recognition that the sentences which allegedly belong to the frame, e.g. the Preface and 6.54, are also mere nonsense.

Several authors have presented objections to this kind of approach to the Tractatus (Hacker 2000; Hutto 2003; Proops 2001; Sullivan 2002; Williams 2004). They claim that it is not clear how the nonsensical sentences of the Tractatus which are allegedly mere nonsense could play a vital role in the dissolution of philosophical problems. How can mere gibberish be useful and enable us to see that so-called philosophical theories consist of nonsensical sentences? Moreover, they demand an explanation as to why Wittgenstein selected this particular portion of nonsense, and not some other, to play that role. ${ }^{3}$ Another objection to resolute readings rests on the fact that Wittgenstein in his later writings criticized the solutions to particular philosophical problems presented in the Tractatus (e.g. the thesis that elementary propositions are independent of each other), pointing out that they are mistaken, not nonsensical. Had he considered his book

\footnotetext{
${ }^{3}$ Some adherents of resolute readings also acknowledge that the defence of their interpretation of the Tractatus requires them to furnish answers to these questions (Goldfarb 1997: 71; Kremer 2001: 45-46).
} 
mere gibberish, this later criticism of the solutions presented in it would not be intelligible.

Some commentators try to present a compromise proposal. It seems that these attempts are based on the belief that the objections levelled against the readings sketched above are serious ones. This compromise approach can be called "elucidatory" (Hutto 2003; McGinn 1999, 2006). ${ }^{4}$ According to the readings of McGinn and Hutto, the Tractatus is not a metaphysical book - it does not contain any theory of reality or language. Its aim is simply to elucidate the functioning of language. To use a term taken from Wittgenstein's later philosophy, the Tractatus consists solely of grammatical remarks. The proponents of this interpretation claim that Wittgenstein's intention while writing the Tractatus was to describe the functioning of language, not to formulate a theory of language. They reject the sort of construal of the Tractatus that says that the sole goal of the book is to prompt the reader into a recognition that so-called philosophical propositions (including the Tractarian Sätze themselves) are nonsensical.

Interpretations of this kind should, in my view, be evaluated positively, as they point out that a correct understanding of what philosophical elucidations amount to is crucial to an adequate reading of the Tractatus - something I would certainly agree with. However, I think that the remarks concerning the nature of the Tractarian elucidations presented by the adherents of these readings are not specific enough. Moreover, these remarks should be supplemented with an interpretation of 6.54. It is also worth adding that some resolute commentators have criticized elucidatory interpretations, claiming them to be ineffabilist readings in disguise (Hutchinson and Read 2006).

The aim of this somewhat sketchy presentation of selected interpretations has only been to furnish a preliminary overview of the subject matter as it pertains to the status of the Tractatus's sentences. As the theme of my article is not the dispute between ineffabilist, resolute and elucidatory readings itself, I will not analyse in detail all the objections raised against these three kinds of interpretation. However, I shall be appealing to the above remarks where necessary, developing some of the particular points of criticism mentioned therein.

\section{The Tractatus on the Sentences of the Tractatus}

In this part of the present article, I shall discuss those fragments of the Tractatus which themselves refer directly or indirectly to its own sentences. I will begin with the remarks contained in the Preface, but will also juxtapose these with other parts of the book - and especially with 4 and 6.54 .

Wittgenstein writes in his Preface that the value of his book lies in its expressing thoughts. Yet this statement is, in my opinion, extremely strange: no one ascribes any value to a book only on the basis of the fact that it expresses thoughts. The fact that every - or at least almost every - book expresses some thoughts is commonly accepted as something obvious. So what could be the point of saying that the value of the Tractatus lies in its expressing thoughts? In my opinion, to answer this question one has

\footnotetext{
${ }^{4}$ McGinn points out that a similar approach to the Tractatus was presented earlier by, inter alia, Rhees and McGuinness (McGuinness 1981; Rhees 1970).
} 
to consider the following question: how can one reconcile the statement that the Tractatus expresses thoughts with the assertions that "the thought is the significant proposition" (TLP 4) and that the final result of reading of the book should be a recognition of its sentences as being nonsensical. On the one hand, if the Tractatus indeed expresses thoughts, it must consist of significant propositions, so it would be a mistake to recognize its sentences as nonsensical. On the other, if the Tractatus consists of nonsensical sentences, it cannot express thoughts. So, if one treats Wittgenstein's remarks as simply assertions expressing propositions, then juxtaposing the Preface, 4 and 6.54 leads to an evident contradiction, which Wittgenstein must surely himself have perceived. In that case, though, how should one interpret the Preface, given 4 and 6.54? I think that the most credible supposition is that Wittgenstein formulated this set of sentences in order to direct the attention of the reader onto questions concerning the status and role of the Tractatus's sentences. In my opinion, he wanted to encourage readers to pose for themselves the following question: do the various sentences they encounter while reading the book express some thoughts (i.e. state facts), or do they serve some other purpose?

As I have already mentioned at the very beginning, on the basis of 4.112 one can draw the conclusion that the Tractatus does not consist of philosophical propositions. If "the result of philosophy is not a number of philosophical propositions", then the sheer fact that it is a philosophical work does not make its sentences philosophical propositions. How, then, should one interpret the statement that it does not consist of philosophical propositions? I would say that given 4.1 (TLP 1961), 4.11 and 4.111, one should acknowledge that its sentences do not represent anything, and conclude from 4 and 4.031 that its sentences do not express thoughts. So, what are its sentences? According to 4.112 , they are elucidations. And what is the function of elucidations? Well, on the basis of 4.112, one can say that elucidations serve to make thoughts clear: "Philosophy should make clear and delimit sharply the thoughts which otherwise are, as it were, opaque and blurred." Summing up the above remarks, one can say that the sentences of the Tractatus were not formulated with the intention of expressing thoughts, but with the intention of making thoughts clear. I shall return in due course to the question of the function of such elucidations.

6.54 is another vital part of the Tractatus which characterizes the function of the sentences of this book

My propositions [sentences] serve as elucidations in the following way: anyone who understands me eventually recognizes them as nonsensical, when he has used them - as steps - to climb up beyond them. (He must, so to speak, throw away the ladder after he has climbed up it.) He must transcend these propositions [sentences], and then he will see the world aright. (TLP 1961)

I would like to focus on three points while discussing 6.54: firstly, on the fact that 6.54 can be treated as a proposition which refers to itself; secondly, on the fact that Wittgenstein emphasizes that the recognition of the Tractatus's sentences as nonsensical must be preceded by the use of them; and thirdly, on the question of how the metaphor of the ladder ought to be construed.

If the reader eventually recognizes the book's sentences as nonsensical, he or she will also recognize 6.54 as nonsensical. One can justify such an interpretation by 
pointing out that there is no indication in the text itself to the effect that 6.54 has an extraordinary status (i.e. belongs to a frame that is meaningful). The recognition that the sentence "the Tractatus's sentences are nonsensical" is also nonsensical is - as it seems - paradoxical. If one were to recognize the nonsensicality of 6.54 on the basis of amongst other things - what it states, then one would have to acknowledge that it is both meaningful and nonsensical, and that is an evident contradiction. So how can one avoid this paradox? The familiar strategies for avoiding it are, of course, as follows: (1) acceptance of the notion of a frame, or (2) abandonment of 6.54. Yet neither seems fully convincing to me. Any adequate interpretation of 6.54 should not merely show that it is an apparent paradox, but should also explain why Wittgenstein formulated this seemingly paradoxical remark. For we should not, after all, assume that Wittgenstein did it unconsciously. It is possible to point to at least two reasons for his having formulated 6.54 in this - at first glance - paradoxical way. Firstly, if philosophy is understood as an activity of formulating philosophical propositions, then it is not possible to overcome philosophy in a philosophical way. That is to say, a philosophical proposition "saying" that philosophical propositions are nonsensical inevitably generates such a paradox. In order to avoid the latter one must - in my view - conceive of the sentences of the Tractatus in a different way. Only if one treats the latter in some other way than assertorically will it be possible to give an interpretation that does not generate the paradox. I will return to this question in Section 8 of this paper. The second possible reason for Wittgenstein's having formulated 6.54 in such a paradoxical way may be the fact that 6.54 can be treated as an exemplification of the nonsense generated by any attempt to formulate a proposition that is supposed to say something about itself (3.332). ${ }^{5}$

So when, according to Wittgenstein, can one recognize the Tractatus's sentences as nonsensical? Well, it does seem that it is not possible to do so before having used them in the process of elucidation. That recognition just is the eventual result of using them. Here is the first part of 6.54 once again:

My propositions [sentences] serve as elucidations in the following way: anyone who understands me eventually [the bold underlined font is mine] recognizes them as nonsensical, when he has used them - as steps - to climb up beyond them. (TLP 1961)

Such a description of the recognition of the Tractatus's sentences as nonsensical allows for two interpretations of their nonsensicality. According to the first, only the process of recognition can be considered in temporal terms. That is to say, the nonsensicality of the sentences is non-temporal: what changes is the consciousness of the reader, not the meaningfulness or meaninglessness of the sentences. The consciousness of the reader alters under the influence of the process of reading. Initially, the reader believes that the sentences have sense; eventually, he or she recognizes them as nonsensical. According to the second interpretation, the very meaningfulness of the sentences of the Tractatus is to be considered in temporal terms. This reading also assumes that a full

\footnotetext{
${ }_{5}^{5}$ A detailed analysis of the possible reasons for Wittgenstein's having formulated this paradoxically sounding sentence could, of course, form the subject of an entire article in its own right.
} 
understanding of the author, such as consists in one's attaining some kind of clarity, renders the elucidations contained in the Tractatus superfluous. That is to say, it leaves them as mere signs no longer used by the reader, where such signs have no meaning (3.328). However, this does not mean that these elucidations, when being used in the process of clarification, are nonsensical. The second interpretation thus allows for the answer to the question of whether the sentences of the Tractatus are nonsensical to be "yes and no". Which answer one gives depends on the perspective from which one is asking. In other words, insofar as the sentences are being used as a means of removing confusions, they do exhibit some kind of sense (i.e. they are not nonsensical). Of course, they do not serve to represent situations: they do not have sense in that particular restricted sense of the term that is concomitant with their being meaningful propositions. Yet if all philosophical problems were dissolved, these sentences would become useless and would lose their sense.

Which interpretation, then, is correct? It might well seem that the first one has to be right. If the meaningfulness of the elucidations depended on whether they are used or not, it would depend on the truth-value of propositions about their use, and this seems to be excluded thanks to 2.0211. However, it is worth noting that 2.0211 is concerned with meaningful propositions in the strict sense, not with sentences that only perform a subsidiary function. Secondly, and more importantly, it is true that the meaningfulness of every sentential sign depends on the truth-value of certain propositions about its use, but only in an entirely trivial sense. In my opinion, then, there are no good reasons to prefer the first interpretation. Moreover, since Wittgenstein treats language as a human construction (4.002) and not only as an abstract structure, the interpretation according to which certain signs lose their meaning at a certain moment seems convincing. The conclusion which should be drawn from the above remarks is thus that there is, perhaps, no one perspective from which the meaning and function of the sentences of the Tractatus can be viewed. In short, while reading the book the sentences contained in it are functioning as elucidations, and so are being used as such, and that is why they are not nonsensical. By contrast, after one has arrived at a definitive termination of the process of reading, one stops using them, as everything has become clear. (Of course, one can say that it was only Wittgenstein's belief that the result of understanding the Tractatus would be one's attaining complete clarity concerning our language). And when one stops using the Tractatus's sentences, then they are recognized as nonsensical.

In order to understand what role the metaphor of the ladder plays in the Tractatus, one must first describe and reflect upon the functions that a ladder performs as an ordinary tool: amongst other things, it is a tool we employ to get to some place otherwise inaccessible to us. That is to say, its value is instrumental, and depends on the circumstances and our aims. A ladder can, for example, join two levels of a building which are not joined by stairs or an elevator. In such a case, the sort of movement that is possible along the ladder will be different from that which is possible on the floors of the two levels. Any movement along the ladder will take place in another dimension. It is worth adding that in order to make it possible to climb the ladder, or at least make it safe, the ladder's base and top must be resting on solid ground. Thanks to the ladder, one can climb upwards to somewhere from which the place where one was prior to 
climbing can be better surveyed. So climbing up the ladder sometimes enables a better orientation with respect to where one has been. Moreover, throwing the ladder away will only be a rational thing to do if one has indeed reached solid ground and is not planning to go back to where one was before.

How can one relate the above remarks to the sentences of the Tractatus? First of all, one should say that these sentences have only an instrumental 'value'. They serve to open up for us the kind of perspective on our language that will enable us to avoid confusions. Certain notations can be perceived as playing the role of such a perspective. Secondly, since the Tractatus's sentences (the rungs of the ladder) function in a different dimension from the bipolar sentences that belong to our ordinary language and other notations (elements of the solid ground), and their 'value' is only instrumental, their use must be fundamentally different from that of those ordinary bipolar sentences. The latter serve to describe reality, whereas the Tractatus's sentences perform another function. The ordinary sentences exhibit 'value' autonomously, because, according to the Tractatus, the fundamental function of every language is to describe reality $(4.001,4.023,4.5)$. By contrast, the 'value' of the sentences of the Tractatus is subsidiary because they essentially serve to allow one to pass from descriptions of reality expressed in one system of notation to those formulated in another. Such notational systems, then, can be recognized as the solid ground on which the ladder rests. It should also perhaps be added that an eventual throwing away of the ladder - a jettisoning of the Tractatus's sentences - would only count as reasonable if one had succeeded in fully orienting oneself with respect to the uses of the expressions of one's language, and the notation thanks to which one had accomplished this was allencompassing. In my view, the belief that it is possible to embrace the sort of perspective that will prevent - in every circumstance - all possible confusions in one's use of language is not very realistic. Moreover, I think that this very belief was perceived by the later Wittgenstein as one of the most problematic assumptions of the Tractatus.

To better understand my approach to Tractarian Sätze, it makes sense to compare it briefly with Diamond's conception of so-called "transitional nonsense". Let us start with the similarities. We both claim that the sentences of the Tractatus are useful at the stage of reading the book (Diamond 1991b: 183). Moreover, we agree that they are useful because they serve to remove confusions arising from the misunderstanding of the logic of our language. So their value is instrumental. There are, however, important differences between Diamond's conception of transitional nonsense and my approach to the Tractarian Sätze. According to Diamond, the sentences of the Tractatus, although useful at the stage of reading the book, are simply mere nonsense. This means that when one recognizes them as nonsensical, one recognizes that they have never been ascribed any sense. So how, for Diamond, does the reader of the Tractatus use the sentences of this book? To explain their use, Diamond compares the role played by them in the Tractatus to the role played by sentences occurring in proofs of the type reductio ad absurdum (1991a: 34-35, 1991c: 276). ${ }^{6}$ According to Diamond, one does

\footnotetext{
${ }^{6}$ I will not discuss here another suggestion of Diamond concerning the role played by Tractarian Sätze, according to which the sentences of the book serve to engender an understanding of "the person who is in the grip of the illusion that there is philosophy in the traditional sense." (2000: 160) The discussion of this question would require a long digression.
} 
not assume, in a reductio proof, that the initial formula has any sense or that the connections between subsequent steps are necessary, but only that that these connections look as if they were necessary. The final result of such a proof is the recognition that, if one wants to retain familiar patterns of mathematical reasoning, one must treat the initial formula as a linguistic construction devoid of any sense. Diamond perceives the role of Tractarian Sätze in a similar way:

my point now is that an account of the role of nonsensical propositions in the argument of the Tractatus can be given in terms of a kind of riddling, a play with sentences of a certain construction, the result of which is the rejection of such sentences as meaningless. (1991a: 35)

The most important difference between Diamond's approach to the Tractarian Sätze and my approach to them lies in the fact that according to me, the sentences of the Tractatus are not nonsensical at the stage of reading the book, as they are then being used as rules of translation. ${ }^{7}$ (I shall elaborate this suggestion further in the ensuing sections). They will become nonsensical only when we - thanks to our having read the Tractatus - subsequently achieve complete clarity as concerns the logic of our language. This clarity consists in the ability to formulate sentences in a notation that is such as to prevent the possibility of any confusion arising. (Of course, from the point of view of Wittgenstein's later philosophy, the belief that it is possible to achieve this goal is to be recognised as a manifestation of a certain philosophical illusion). So the difference lies in the fact that according to Diamond, what alters during the process of reading the Tractatus is our perception of these sentences (in that at the beginning they are perceived as meaningful even though they are not, while in the end we are set free from all such confusions and perceive them as nonsensical), whereas on my interpretation, what changes is their status (in that at the outset they are not nonsensical, as they are indeed being used for something, while a definitive end to the process of reading the book brings with it a new situation, in consequence of which they become nonsensical). The sentences in question, I would say, become nonsensical for the reader who has grasped Wittgenstein's intention, because there is no longer any need to use them.

The above remarks concerning those parts of the Tractatus that refer to the sentences of the book itself show how ambiguous the word "Satz" can be. On the basis of these and other parts of the work, one may conclude that the word "Satz" can be used to signify a bipolar proposition, a tautology, a contradiction, a mathematical equation, a rule of translation, or mere nonsense (cf. Diamond 2014: 21-22). ${ }^{8}$ Alerting oneself to

\footnotetext{
7 This does not, however, mean that they count as meaningful (bipolar) propositions.

${ }^{8}$ Wittgenstein's use of the term "Satz" in the Tractatus is very peculiar. At first glance, it seems that it is used as a technical term to signify only truth-functions of elementary propositions $(6,6.001)$. However, he also uses the term to speak about mathematical equations $(6.21,6.2321,6.2341)$ (also of course characterizing these as "Scheinsätze") and nonsensical sentences $(4.003,6.53)$. (The role of the so called subsidiary propositions such as mathematical equations and rules of translation is discussed by Diamond and Kremer (Diamond 2014; Kremer 2002)). I think that this ambiguity was intended by Wittgenstein, but I shall not discuss this here as it is not necessary for understanding the main idea of my interpretation.
} 
that ambiguity then prompts the following question: into which of these categories are the Tractatus's sentences themselves to be put?

\section{Elucidations as Rules of Translation}

The question with which the previous paragraph ended provides a good starting point for a presentation, in rough outline, of my own interpretative approach. Generally, what I wish to claim is that the philosophical elucidations contained in the Tractatus are rules of translation. ${ }^{9}$ What this means is that the Tractatus instructs us on how to substitute certain expressions for other expressions. In some cases these rules are used to translate expressions of ordinary language into other expressions of the same type, while in others they translate expressions of ordinary language into expressions of a symbolic notation. ${ }^{10}$ In other words, many sentences contained in the Tractatus are definitions: "3.343 Definitions are rules for the translations of one language into another." (TLP) 11 Of course, from the grammatical point of view, philosophical elucidations do not differ from indicative sentences which serve to assert facts. The difference between these kinds of speech act lies in the use of the sentences. Some of the sentences are used to describe reality and are true or false, while others are used to translate certain sentences formulated in one notation into sentences formulated in another. ${ }^{12}$

I would like to point out here that it is not implausible that the term "elucidation" is used in the Tractatus in different ways in different contexts. That is, "elucidations" as mentioned in 3.263 refers to something different from "elucidations" as mentioned in 4.112 or $6.54 .{ }^{13}$ Undoubtedly, there is a certain difference. 3.263 speaks only about elucidations concerning the meaning of names, whereas 4.112 speaks about all such elucidations which are philosophical in their character. It seems that the former would

\footnotetext{
${ }^{9}$ Of course, not all sentences contained in the Tractatus belong to this group; for example, the following sentence is obviously not a rule of translation: "...one speaks without knowing how the single sound is produced." (TLP 4.002)

${ }^{10}$ According to Goldfarb and Kuusela, the Tractatus can be interpreted as an attempt to present a perspicuous logical notation (Goldfarb 1997: 71-72; Kuusela 2011: 133-138). However, as Goldfarb points out, Wittgenstein did not in fact construct any notation of his own. A similar observation is made by Ostrow (Goldfarb 1997: 71; Ostrow 2004: 9).

113.343 is, of course, also a definition.

12 The right and proper notation will be that which allows one to avoid producing nonsense (5.534). Yet one should not expect to be able to define such a notation in terms of geometric patterns: its aim is rather to show in a perspicuous way - similarities and differences in the $u$ se of different expressions $(3.325,3.326)$. Hence, it seems that it need not be identified with a formal language. In my opinion, then, it can form a part of a natural language (though such an interpretation could perhaps be questioned on the basis of 4.002). This issue can be explicated using the following example. One can avoid various confusions by translating sentences such as "the Evening Star is Venus", "the Evening Star is bright", etc., into sentences such as "the Evening Star is identical with Venus", "the Evening Star has the property of brightness", etc. which also belong to natural language. One can avoid, for example, treating both of these sentences as having the same logical form - as consisting of a name and a one-place predicate. However, a positive or negative answer to the question of whether the right and proper notation must or need not be identified with a formal language will not settle the question of whether my proposal of understanding the sentences of the Tractatus as rules of translation is right or not.

${ }^{13}$ I owe this suggestion to an anonymous reviewer. It is also worth adding that, for example, according to Kuusela the use of the word "elucidation" in 4.112 is dissimilar to its use in 6.54 (2006).
} 
not have been called "philosophical" by Wittgenstein. Moreover, although the latter also seem to elucidate the meaning of certain expressions, the expressions which they elucidate are formal terms such as "fact", "object", "proposition", etc., and not names. In this and the following sections, I will try to show that in spite of the difference I have just pointed to, both elucidations of the type mentioned in 3.263 and those of the type mentioned in 4.112 are similar in a certain important respect - namely, that they amount to rules of translation.

Is the interpretation of Tractarian elucidations according to which they are rules of translation convincing? The simple fact is that Wittgenstein does not explain what he means by the term "philosophical elucidation". Moreover it seems that he contrasts elucidations with definitions:

3.26. The name cannot be analysed further by any definitions. It is a primitive sign.

3.263. The meanings of primitive signs can be explained by elucidations. Elucidations are propositions which contain primitive signs. They can, therefore, only be understood when the meanings of these signs are already known. (TLP)

I do not think that the above remarks entitle us to draw the conclusion that it is impossible to give definitions (in any sense of this word) of primitive signs. Primitive signs cannot be analysed with definitions, but this does not mean that one primitive sign used in a certain way cannot be substituted for by another sign used in the same way - the rule allowing such a substitution is, according to the Tractatus, a definition. Remark 3.263 clearly states that elucidations in themselves do not present us with any new knowledge. To understand the signs whose meanings are being elucidated for our sake, we must understand these elucidations, but to understand the latter we must already know the meanings of the signs. This shows that elucidations play a completely different role from that of meaningful propositions. They do not express thoughts, but show how one expression of a certain thought can be substituted for by another expression of the same thought.

Is this construal of elucidations compatible with the statement that they are Sätze? I think so, and shall present two arguments in support of this claim. Firstly, I shall present some general considerations which show that this is so; then I shall seek to reinforce my claim by considering a particular case.

As I said earlier, Wittgenstein uses the word "Satz" not only to signify a bipolar proposition, but also a tautology, a contradiction, a mathematical equation, a rule of translation, or mere nonsense $(4.003,6.21,6.2321,6.2341,6.53)$. (Of course, he points out that mathematical equations, not being truth-functions of elementary propositions, should be rather called "Scheinsätze".) So, the mere fact that elucidations of names are called "Sätze" in 3.263 does not settle the question of whether they are meaningful propositions (logical pictures). This question should be decided via a proper understanding of 3.263 and its surrounding remarks. Incidentally, it is worth noting that the Wittgensteinian formulation of the context principle appears immediately after 3.263, and that this principle requires that we consider the meaning of a given word only in the context of a proposition. So, the meaning of the word "Satz" in 3.263 should itself be 
considered in the light of this remark, and one need not assume that it signifies a bipolar proposition there.

Now I turn to my second argument. Suppose that someone says "this is red", while pointing to some red fabric. These words can be treated as a statement of a certain fact, but they can also be treated as an elucidation of the meaning of the word "red" - where, in this second case, they perform the role of an ostensive definition of the word "red". And so the words "this is red", together with the gesture of pointing and the object pointed to, can be used to elucidate the meaning of the word "red". In this case, this sentence is not a proposition stating a fact, but a rule of use for the word "red". I would suggest that although the sentences used to express elucidations can also be used to state facts, and the elucidations contained in the Tractatus are - from the point of view of traditional grammar - indicative sentences, elucidations do not state facts. The explanation is simple: the logico-syntactic applications of the same signs are different in the two above-mentioned cases (cf. 3.327). The same propositional sign is a meaningful proposition in the first case, and a pseudo-proposition in the second. (I wish to stress that this interpretation is not incompatible with Wittgenstein's remark that elucidations are Sätze, because pseudo-propositions can, as I have already argued, also be treated as Sätze). In my opinion, confusions concerning the status of the Sätze of the Tractatus have their source in the fact of the apparent logical form of Tractarian elucidations being treated as their real logical form (cf. 4.0031).

It is worth noting that several commentators - e.g. Black, Ishiguro and Hacker (Black 1964; Ishiguro 1969; Hacker 1975, 1999; see also Bar-Elli 1997) - have claimed that the concept of elucidation discussed in 3.263 may somehow be problematic, or require a specific characterization of the sentences which play the role of elucidations. According to Black, Wittgenstein's approach to elucidations of names makes "common reference by speaker and hearer... mysterious" (1964: 115), at least from a philosophical point of view. Ishiguro claims that one must grasp the truth of elucidatory sentences in order to be able to understand the senses of all the sentences in which the names being elucidated occur (1969: 33-34). Ishiguro's claim seems strange, however, given that, according to Wittgenstein, a proposition's having a sense cannot depend on whether some other proposition is true (2.0211). Hacker suggests that 3.263 is evidence that Wittgenstein in the Tractatus did not see that certain sentences can be construed either as factual (bipolar) propositions or as grammatical rules. According to Hacker, 3.263 blurs the distinction between these (1975, 1986: 77-78, 1999). In order to justify his point, Hacker appeals to Wittgenstein's later remarks (Waismann 1979: 209-210, 246; Wittgenstein 1975: §6).

The content of 3.263 may, in fact, seem problematic. If one were to formulate elucidations in order to explain the meanings of names to someone who did not understand them, then the explanation of the meaning of these names by means of sentences whose understanding presupposed knowledge of the meaning of these names would be completely useless. However, 3.263, taken together with subsequent remarks (3.3, 3.314), shows that for Wittgenstein, elucidations of the meanings of names cannot be given independently of determining how they are used in sentences (cf. Ishiguro 1969). But what are the sentences to which these remarks are referring? It seems that they refer to meaningful sentences. And yet, if that were to count as a satisfactory answer to the question of what elucidations are, then my interpretation, according to which they are not meaningful sentences but rules of translation, would be mistaken. So 
what is to stop one claiming that elucidations are meaningful sentences? As I have already stated, they play a different role, because they serve different purposes (Diamond 2000: 172). Interestingly, the remark which immediately precedes 3.263 says that "what does not get expressed in the sign is shown by its application" (3.262). This remark can be construed as pertaining to propositional signs that are used on one occasion as meaningful propositions, and on another as elucidations. The function of sentences playing the role of meaningful propositions is to state certain facts, not to elucidate the meaning of the terms occurring in these propositions. (For example, the function of the sentence "Putin met Obama" may be to state that Putin met Obama, in which case its function is not to elucidate the meanings of the names "Putin" and "Obama"). By contrast, the function of sentences playing the role of elucidations is not to state facts. Elucidations qua elucidations do not state facts, because they serve to explain the meanings of names occurring in the sentences used as elucidations, and the meaning of these names would have to already have been fixed and be known, for the sentences to be used to state facts. So, if the sentence "Putin met Obama" were to elucidate the meanings of the names that occur in it, this sentence, insofar as it performed the role of an elucidation, would not state any fact.

The above interpretation raises some questions, of course. What ways of using propositional signs can count as elucidatory? Can propositional signs used in such ways be characterized as rules of translation? Some commentators think that the elucidatory use of propositional signs consists in the fact that certain propositional signs (sentences) are used as ostensive definitions (Hacker 1975, 1986). ${ }^{14}$ Other commentators criticise such an interpretation (Helme 1979). The Tractatus does not answer the questions posed above in any straightforward way, but one can speculate as to how one is supposed to understand the elucidatory use of sentences. I guess that when a propositional sign is used as a rule of projection, then it is used as an elucidation, not as a meaningful proposition. And what does the use of a certain sentence as a rule of projection consist in? It seems that it consists in this: that its use serves to assign objects to names. ${ }^{15}$ So, for example, the sentence "Putin met Obama", used as an elucidation, assigns appropriate persons to the names "Putin" and "Obama". Wittgenstein, in the Tractatus, did not consider in detail how one assigns meanings to names. He recognized that it is a question of language use, but did not describe the kind of language use it involved. Turning now to the second of the above questions, I think that it should be answered in the affirmative because, according to 4.0141, a rule of projection can itself be said to be a "rule of translation" of sorts. Calling the relation between names and objects designated by them a relation of translation may, of course, seem strained; nevertheless, one ought to be prepared to recognise this approach to rules of translation as significantly more acceptable, in the light of the fact that the relation of translation as conceived in that remark has the character of a one-to-one correspondence.

The above considerations show that Tractarian elucidations should not be treated as having been designed to play the role of propositions (or pretend that they do so). The elucidations contained in the Tractatus are not sentences that attempt to state what can

\footnotetext{
${ }^{14}$ Certain fragments from Schlick's Meaning and Verification can be read as supporting an interpretation of the Tractatus as treating elucidations of names as ostensive definitions (Schlick, 1936).

${ }^{15}$ A similar thought seems to have been expressed by Anscombe (1965: 154).
} 
only be shown (as opposed to Hacker), nor are they merely nonsensical sentences that only pretend to do so (contra Conant and Diamond). These elucidations, which are pseudo-propositions, instruct us about how certain expressions can be substituted for by other ones. This is expressed by the use of the sign for identity: the latter joins the original expression with the expression that is to substitute for it. However, according to Wittgenstein, such a sentence is not a proposition which asserts that these expressions have the same meaning:

6.2322. The identity of the meaning of two expressions cannot be asserted. For in order to be able to assert anything about their meaning, I must know their meaning, and if I know their meaning, I know whether they mean the same or something different. (TLP)

Such identities do not say anything: they only allow us to substitute one form of notation for another. They can prove useful when dealing with a language which contains different expressions having the same meaning. The elucidations in question may be employed to construct a notation in which every meaning is expressed by just one term. Thus, they enable us to construct the sort of notation in which everything conveyable using ordinary language can be said perspicuously.

Rules of translation, in which the sign for identity occurs, do not convey any new knowledge, but only serve to clarify our way of understanding reality: the existence of a correct notation would render these rules superfluous. Such rules may be used to prevent confusions which arise, firstly, from the fact that different expressions of ordinary language have the same meaning and, secondly, from the fact that sometimes one expression has different meanings. ${ }^{16}$

\section{The Role of the Sign for Identity in the Tractatus}

If we are to better understand the status of elucidations, it is worth briefly considering the role of the sign for identity in the Tractatus. As Fogelin and Kremer rightly note, two uses of that sign are explored there (Fogelin 1983; Kremer 2007: 154-155) Firstly, it can be treated as supposedly signifying the relation of identity holding between objects, and secondly, it can figure in definitions (understood as rules of translation). What the use of the sign for identity in definitions shows is that one expression can be substituted for by another in that both stand for the same thing - i.e. have the same meaning.

One might say that in the first case, the expressions appearing on both sides of the sign for identity can be treated as used to be the case in suppositio formalis, whereas in the second such expressions are used as in suppositio materialis. ${ }^{17}$ According to

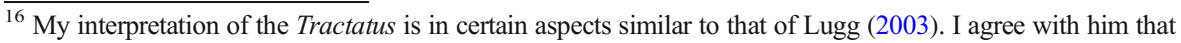
the sentences contained in the book do not convey any information, but cannot concur that in spite of that they still express a form of truth.

${ }^{17}$ I use the phrase "could be treated" because, according to Wittgenstein's analysis, sentences of the form " $\mathrm{a}=$ $a "$ and " $\mathrm{a}=\mathrm{b}$ " do not actually assert anything.
} 
Wittgenstein, the purportedly objectual use of the sign of identity can be eliminated by introducing a convention which states that different names stand for different objects and different variables have different ranges of values (variables should be interpreted in the exclusive way). So, a sentence of the form " $f(a, b) \wedge a=b$ " should be written in the following way " $f(a, a)$ ", a sentence of the form " $f(a, b) \wedge \sim a=b "$ as " $f(a, b)$ ", and a sentence of the form "Vx $(f(\mathrm{x}) \wedge \Lambda \mathrm{y}(f(\mathrm{y}) \rightarrow \mathrm{x}=\mathrm{y}))$ " as " $\mathrm{Vx}(f(\mathrm{x}))$ ". White and Lampert $\&$ Säbel discuss in detail the question of the elimination of the supposedly objectual use of the sign for identity (Lampert and Säbel 2016; White, 1977-1978; see also Fogelin 1983; Kremer 2007).

If one juxtaposes the above remarks about the conception of identity in the Tractatus with the sign vs. symbol distinction, then the following conclusion seems to be evident: the sign for identity can be either a symbol featuring in definitions, in the sense of a symbol joining expressions used according to suppositio materialis, or a useless sign to which no meaning has been given (3.328). Conceiving of the role of the sign for identity in such terms would seem justified when dealing, for example, with statements about the number of objects having a certain property, as statements of this kind can be formulated without using the sign for identity.

So, can one say that the sign for identity is used in a meaningful way in mathematical equations and definitions (rules of translation)? The answer depends on whether one recognizes equations and definitions as an indispensable and ineliminable element of language. In my opinion, the Tractarian attitude towards equations and definitions is ambivalent. On the one hand, Wittgenstein recognizes that equations and definitions play a certain role in language (Diamond 2014; Kremer 2002): they allow the substitution of one sign for another $(4.241,6.23,6.24)$. Such sentences, for example equations, serve to enable us to pass from certain non-mathematical propositions to certain other non-mathematical propositions. (For instance, thanks to the equation " $4 \times$ $8=32$ ", one can pass from the proposition saying that we have 4 shelves, and 8 plates on every shelf, to the proposition that we have 32 plates). So, since the sign for identity is used in such sentences, it cannot be superfluous - and, consequently, must be meaningful. On the other hand, Wittgenstein emphasizes that equations and definitions are pseudo-propositions which express no thought and state nothing $(6.2,6.21,6.2322)$. Equations and definitions are "only expedients in presentation" (TLP 4.242) - and, moreover, in life one has no need for them on their own (6.211). That is to say, they perform their function only together with meaningful (bipolar) propositions. One can even say that definitions and equations are completely superfluous from the point of view of the subject who is using the right and proper notation and has mastered it completely. To put it another way, definitions and equations can be abandoned once one has completely mastered the appropriate notation. Moreover, it is especially worthwhile to note that the role of definitions is different from that of tautologies and contradictions. Tautologies and contradictions, as truth-functions of elementary propositions, are ineliminable elements of every symbolism (i.e. every notation), whereas definitions could be eliminated, if we were to use only the kind of notation in which every sign has a different meaning.

To sum up, according to Wittgenstein, definitions and equations play only an auxiliary role in our notation: in principle, they could be eliminated. (This last remark is undoubtedly right insofar as it concerns definitions, but whether it is in fact possible to eliminate equations is a question I would not wish to try to settle here). They play no 
role in language on their own, express no thoughts, and it makes no sense to ascribe to them truth or falsity. In my opinion, one can only say that they are not nonsensical if one treats them as connected with meaningful (bipolar) propositions - only then do they have a use. By contrast, when isolated from meaningful propositions, the sentences that are ordinarily used as definitions and equations become signs to which no meaning has been given.

\section{The Plausibility of Treating the Sätze of the Tractatus as Rules of Translation}

The question of just how plausible it is to construe Tractarian Sätze as rules of translation can only be decided by a study of particular cases. The first thing that follows from this is that it is impossible, in as short a text as a single article, to prove that my interpretation is right in its entirety. Secondly, it may turn out that my interpretation is only partially right or adequate. That is, it might conceivable emerge that only some sentences of the Tractatus should be understood as rules of translation. I shall therefore try below to show only that interpreting the principal Sätze of the Tractatus as rules of translation represents a natural and plausible reading of that text.

Consider the seven main Sätze of the Tractatus:

1. The world is everything that is the case.

2. What is the case - a fact - is the existence of states of affairs. (1961)

3. The logical picture of the facts is the thought.

4. The thought is the significant proposition.

5. A proposition is a truth-function of elementary propositions. (An elementary proposition is a truth-function of itself.) (1961)

6. The general form of a truth-function is $[\underline{p}, \xi, \mathrm{N}(\xi)]$. This is the general form of a proposition. (1961)

7. Whereof one cannot speak, thereof one must be silent. (TLP)

All of these Sätze in fact have the form of identity sentences. They can be presented in the following way:

The world $=$ everything that is the case.

What is the case $=\mathrm{a}$ fact $=$ the existence of states of affairs.

The logical picture of the facts $=$ the thought.

The thought $=$ the significant proposition.

A proposition $=$ a truth-function of elementary propositions.

The general form of a truth-function $=[p, \xi, \mathrm{N}(\xi)]=$ the general form of a proposition.

[That] whereof one cannot speak $=[$ that $]$ whereof one must be silent.

This reading takes the Sätze of the Tractatus at - so to speak - face value. It is quite natural to interpret the word "is" in this context as the sign of identity. Reformulating Tractarian elucidations in this way shows that they are not metaphysical propositions 
(and, indeed, that they are not propositions at all) and that they do not convey any content. These identities serve only to show how to substitute certain symbols for other symbols. And so, when the word "world" is used in a meaningful proposition, we can substitute for it the expression "everything that is the case", and the resulting proposition will also be meaningful. This will also be the case with the word "thought" and the expression "logical picture of the facts", and so on.

It is worth adding here that my interpretation is not incompatible with the fact that according to the Tractatus, words such as "fact", "proposition", "object" and the like express formal concepts, and should be substituted with appropriate variables.

So let us now consider a few contexts in which one expression can be substituted for another. I would like to begin with " 1 . The world is everything that is the case", together with the sentence "There are many scientists in the world". Thus, according to my reading, the former sentence allows us to translate the latter into the sentence "It is the case that there are many scientists". One can raise two objections against my reading: (1) according to the Tractatus, the word "world" does not occur in meaningful propositions; (2) the translation presented above is incorrect. ${ }^{18}$ The first objection cannot mean that the sentence "There are many scientists in the world" is nonsensical, because according to the Tractatus all of the propositions of everyday language are completely in order (5.5563). It can only mean that the word "world" does not occur in completely analysed meaningful propositions. If the first objection comes down to this claim, I agree with it. The expression "in the world" is redundant in the sentence being considered. This can be justified in the following way: one can transform the sentence "There are many scientists in the world" into the sentence "Among everything that is the case, it is the case that there are many scientists" using a rule of translation according to which "The world = everything that is the case", with the resulting sentence then being transformed into "It is the case that there are many scientists", and the latter, in turn, into "There are many scientists". (These last two steps are based on intuitive rules which I shall consider later).

One might claim that these transformations are incorrect - especially the first one. (This is the second objection.) The first step might seem wrong because, according to the critic, the resulting sentence should be "There are many scientists in everything that is the case". If one were to treat English (or any other natural language) as a simple formal language, then this objection would be justified. However, transformations in English and other natural languages are not as straightforward as they are in such simple formal languages as, for example, the language of the classical propositional calculus. The reason for this is the fact that not all criteria of linguistic correctness are based on simple combinatorial rules; for example, although the expressions "the world" and "everything that is the case" are both nominal phrases, the expression "in the world" is correct, but the expression "in everything that is the case" seems not to be. It is worth noting that when our paraphrase of a sentence in a natural language is based on a certain rule of translation, we often change the grammatical structure of the original sentence. (If one's rule is that "to differ = to be dissimilar", and the original sentence is "These two apples differ from each other", then the correct paraphrase will be "These two apples are dissimilar", and not "These two apples are dissimilar from each other". It should be added that this problem cannot be avoided by accepting, as a correct rule, that "to differ from each other

$\overline{18}$ These objections were raised by an anonymous reviewer. 
= to be dissimilar", because the sentence "The first apple differs from each other to the second" is not a correct paraphrase of the sentence "The first apple is dissimilar to the second"). This, then, is the reason why my paraphrase need not be considered incorrect. Moreover, provided that one agrees that the expressions "the world" and "everything that is the case" have the same meaning, the sense of the sentence "There are many scientists in the world" will seem to be the same as that of the sentence "Among everything that is the case, it is the case that there are many scientists".

The second step of my paraphrase is, in my opinion, uncontroversial. It is based on the rule which allows one to infer the proposition "It is the case that $s$ " from the proposition "Among all $p$ such that it is the case that $p$, it is the case that $s$ ". (Here " $p$ " is a propositional variable, meaning that it can be substituted with propositions, " $s$ " is a propositional constant, meaning that it is a certain definite proposition, and "it is the case that ..." is a truth-function that is such that the formula "it is the case that $p \equiv p$ " is a tautology. It should also be added that the quantifier used in this proposition is neither objectual nor substitutional, because, according to Wittgenstein, sentences are not names, and the expression "all $p$ such that it is the case that $p .$. " is not used to quantify over sentences conceived as strings of signs. ${ }^{19}$ ) This rule is analogous to the principle which says that the proposition "Among all the apples there are, this apple is red" entails the proposition "This apple is red". The last step of my paraphrase is correct provided that propositions of the form " $p$ " are logically equivalent to propositions of the form "It is the case that $p$ ".

Summing up the discussion as it pertains to our first example of translation, I would say firstly that it seems quite plausible that my paraphrase is correct, and secondly that my reading shows that, according to the Tractatus, the word "world" is redundant in the final analysis. However, this does not mean that these propositions of ordinary language in which the word "world" occurs are devoid of sense. My considerations rather show that, according to Wittgenstein, someone who would be inclined to think that the proposition "There are many scientists in the world" says, in principle, something more than the proposition "There are many scientists" does, would be suffering from an illusion caused by a certain conceptual confusion.

Let us now turn to another example of translation. If we take " 2 . What is the case - a fact - is the existence of states of affairs", together with the sentence "No fact confirms his words", then what the former does is allow us to render the latter into the sentence "There are no states of affairs which confirm his words". One might object that this translation is not correct, because the resulting sentence should be "No existence of states of affairs confirms his words", and not "There are no states of affairs which confirm his words". However, if the remarks presented above concerning the application of translation rules to natural languages are right, there is no reason to suppose that my paraphrase is incorrect. More particularly, this is because expressions of the form "The existence of the state of affairs that $p$ confirms y" can be paraphrased as "There is a state of affairs that $p$ which confirms y". Thus, for example, the expression "The existence of the state of affairs that he eats too much cake confirms our hypothesis" can be paraphrased as "There is a state of affairs that he eats too much cake which confirms our hypothesis".

\footnotetext{
${ }^{19}$ The conception of a form of quantification which is neither objectual nor substitutional has been presented by Grover, who refers to it as "propositional quantification" (1972).
} 
The rule of translation discussed in the preceding paragraph (i.e. "2. What is the case - a fact - is the existence of states of affairs") allows us to also translate the sentence "If this is a fact, that also will be a fact" into the sentence "If these states of affairs exist, then those states of affairs will exist". Finally, let us consider one more example, taking "4. The thought is the significant proposition" together with the sentence "Every thought has its consequences". The former allows us to translate the latter into the sentence "Every significant proposition has its consequences".

What kind of confusions can be avoided by providing such translations? First, as I have already pointed out, these translation can show that certain expressions, e.g. "the world", are redundant, and that the sentences in which they occur say nothing more - in spite of our inclination to think the opposite - than some sentences in which they do not occur. Second, these translations allow one to see that certain sentences of ordinary language which differ in an external form from each other have the same sense. In particular, they allow one to notice that the same formal concept is expressed in ordinary language by different expressions: ones that seemingly contain different variables, but which in fact contain one and the same variable. ${ }^{20}$ So, the use of these rules of translation allows one to see what logical connections hold between sentences of a natural language. It should be added that, according to my interpretation, the rules of translation which make up the Tractatus not only allow one to translate certain sentences of a natural language into other sentences of that natural language, but also to translate sentences of a natural language into a certain symbolic notation.

\section{Objections}

One of the greatest challenges for my interpretation is the problem of how to construe Tractarian elucidations that concern the metaphysical subject, ethics, aesthetics, and the mystical. How should one interpret, for example, the following sentences?

5.631. The thinking, presenting subject; there is no such thing.

6.522. There is indeed the inexpressible. (TLP)

These sentences seem to resemble classical metaphysical theses, and for that reason one could argue that the only possible strategies for reading them or others like them are to

\footnotetext{
${ }^{20}$ Consider the sentences "There is not any fact that confirms his words" and "There are no states of affairs that confirm his words". It can be shown that the same variable occurs in these sentences, provided that certain intuitively acceptable transformations are made. The sentence "There is not any fact that confirms his words" can be transformed into "There is not any $p$ such that $p$ is the case and $p$ confirms his words". This transformation can be made in two steps. First, the expression "there is a fact which is $F$ " can be rendered by the expression "there is something which is the case and this something is $F$ ". (This step can be justified by the rule that "a fact = what is the case". However, applying the rule, as in the cases discussed before, requires making certain changes to the grammatical structure of the sentence - changes that must be made, as the expression "There is what is the case which is $F$ " is grammatically incorrect.) Second, the latter expression can be made logically more perspicuous if the word "something" is substituted with a propositional variable and the predicate "... is the case" with the operator "it is the case that ..."; one may otherwise be inclined to interpret the original sentence as suggesting that facts and propositions are special kinds of object.
} 
acknowledge (1) that Wittgenstein's approach to metaphysics was not consistent, or (2) that the Sätze of the Tractatus attempt to convey what cannot be said, or (3) that these sentences of the Tractatus, like all other sentences contained there, serve only to show that they are nonsensical, as some of their elements do not have any meaning. However, I believe that my interpretation of the Tractatus can be defended against such a critique. First of all, the sentences quoted above should be interpreted in the light of a broader context. 6.522 consists not only of the quoted sentence, but also of the sentence which follows: "This shows itself; it is the mystical". Moreover, this "thesis" that the inexpressible exists is, to almost all effects and purposes, straightforwardly countered by the sentence: " 6.5 The riddle does not exist" (TLP). 5.631 consists of two sentences, the second - the one which has not been quoted - being much longer than the first. According to my interpretation, 6.522 can be elucidated in the following way: Wittgenstein is not saying that the inexpressible exists (cf. 6.522) or that it does not exist (cf. 6.5): he is merely pointing out that if one is inclined to use the words "the inexpressible", one may substitute "the mystical" for them. 5.631 should be read as a remark to the effect that the expression "the thinking, presenting subject" should not be substituted for by the name of any object. In other words, 5.631 points out that the expression "the thinking, presenting subject" does not play the role - contrary to its apparent form - of a referring expression. $^{21}$

Nevertheless, the most problematic issue from the point of view of my interpretation seems to lie with the attempt to read 6.54 along such lines. Should one treat this fragment of the Tractatus as a rule of translation? It may seem to consist of ordinary propositions: ones which are about all the preceding sentences of the book. However, I think that this fragment can be understood in a different way. Its first sentence can be read as a rule of translation that allows the expression "the elucidatory sentences of the Tractatus" to be substituted for by the expression "the sentences of the Tractatus which will come to be recognized as nonsensical". Because of the fact that the nonsensicality of a sentence is nothing other than its lacking any use whatsoever, this very sentence (i.e. the first of 6.54) turns out to be nonsense once one has arrived at the definitive end of the process of reading: as a rule of translation itself, it will lose its use once all confusions and unclarities have been removed thanks to the prior use of rules of translation contained in the Tractatus. However, it should be emphasized that so long as the process of reading the book has not finished, this sentence will have a definite function - as a rule of translation. So, as I have already mentioned, my interpretation approaches the question of the nonsensicality of the Tractatus's sentences in a radically different way from both ineffabilist and resolute readings.

According to the interpretation proposed here, one and the same sentence of the Tractatus can perform a certain function at one stage of the process of reading and for that reason not be nonsensical, while becoming useless at another stage and being, for that reason, nonsensical then. So, the dispute as to whether a certain sentence of the Tractatus is nonsense or not does not have any definite sense until we have established what stage the process of reading is at. As I have already mentioned, my approach to the question of the nonsensicality of the Tractatus's sentences is supported firstly by the fact that Wittgenstein explicitly says that the reader is to eventually recognize his sentences as

\footnotetext{
${ }^{21}$ Here it is worth noting that Wittgenstein in his later writings indicates that in some instances the use of the word "I" does not serve to identify the person who uses it (Wittgenstein 1960: 66-67).
} 
nonsensical, and secondly by the fact that he avails himself of the metaphor of the ladder, which suggests that the sentences of the book possess a use at a certain stage of one's reading the book, and consequently are not nonsensical at that stage. However, it should be stressed one more time that the use of sentences of the Tractatus is completely different from that of sentences that describe facts - that is, from bipolar propositions. The sentences of the Tractatus, in contrast to bipolar propositions, stand to lose their use once all propositions have been translated into a right and proper notation.

One could raise further objections to my reading of 6.54. (I owe the suggestions below to an anonymous reviewer). First, it is not obvious that if one stops using the rules of translation contained in the Tractatus once complete clarity has been achieved thanks to their prior use, then these rules will become completely useless, and hence nonsensical. One could justify this objection by pointing out that these rules may prove useful in the future. My answer to this objection is that they could prove useful in the future only if, after the definitive end to the process of reading the Tractatus which yields a complete removal of all instances of unclarity and confusion, some new philosophical problems, generated by new instances of unclarity and confusion, could arise. However, this would mean that - in opposition to Wittgenstein's own conviction - the result of the correct interpretation of the Tractatus is not a definitive solution of philosophical problems (cf. Preface). In my opinion, Wittgenstein, while writing the Tractatus, thought it possible to achieve such a state in which no philosophical problems could arise. Of course, this thought, as I have already pointed out, can be criticised as unrealistic and dogmatic, but it does seem to have been expressed in the Preface. It is worth adding that after having translated all the sentences which could generate confusion into sentences which are completely clear, any further paraphrases of these completely clear sentences would be superfluous, as they could not make our language any clearer; hence, the rules of translation would then be quite useless.

One could also criticise my reading of 6.54 by arguing that it is not clear why the aim to be achieved via the use of the rules of translation requires throwing them away. Moreover, to justify such an objection, one could appeal to an analogy between reading the Tractatus and building a house. Once we have finished building the house, we can throw away the tools which we employed to accomplish that, but this does not mean that our goal will be achieved only if we throw them away. However, I think there are important differences between these two cases. The tools which serve to build a house can serve many other purposes. Throwing away material tools usually means putting them in a waste bin, whereas the Tractarian rules of translation serve only to avoid confusions - they allow one to translate sentences of ordinary language into a perspicuous notation. Throwing away linguistic expressions, e.g. rules of translation, does not consist in our putting them in a certain place: it rather consists in the fact that we cease using them. When we have finished the process of clarifying our language, we will cease using the rules of translation. To throw away these rules is just to cease using them - nothing more. It is not to make some additional mental gesture.

\section{Appendix: Kuusela's Reading Vs. My Reading}

Kuusela has presented a reading of the role of the Tractatus's sentences which is in some respects similar to my interpretation (Kuusela 2012). He claims that the main aim 
of the Tractatus is the dissolution of philosophical problems through the translation of those sentences of our ordinary language that generate confusions into sentences formulated in the right and proper notation. So what function do the book's sentences perform, according to Kuusela? They are pseudo-syntactical sentences and serve to introduce the correct notation: that is, they help us to construct the sort of notation in which, for example, the words "object" and "property" will be substituted with the appropriate variables, and sentences formulated in such a notation will not generate any confusions or have a sense that is anything other than completely clear. For that very reason, the sentences of the Tractatus can be called "elucidations". However, it should be noted that according to Kuusela, Wittgenstein recognizes these sentences as simply nonsensical. Although I find Kuusela's approach interesting and think that he is right to emphasize the importance of the role played by the concept of translation in the Tractatus, I am less sure about his conception of the function of its sentences themselves.

Firstly, it is not clear how nonsensical sentences can be helpful in the construction of an appropriate notation. If the whole story about the Tractatus's sentences were simply that they are mere nonsense, then it would be difficult to explain how they could serve as useful devices that would help to translate our ordinary sentences into an alternative notation. My interpretation shows that one need not abandon the austere conception of nonsense according to which every instance of nonsense is mere nonsense, and then be obliged to embrace the notion of substantial nonsense, in order to explain the usefulness of these sentences. Instead, one need only acknowledge that they are in some sense meaningful at one stage of the process of reading, and nonsensical at another - i.e. after a definitive end to that process has been arrived at. Secondly, Kuusela himself advocates a resolute reading, it seems, but calling the Tractatus's sentences "pseudosyntactical sentences" is, in my view at least, incompatible with that approach. If the sentences of the Tractatus are recognized as mere nonsense, then it is surely incoherent to seek to place them in a certain logical category - for example, that of pseudosyntactical sentences. It would appear that in describing the sentences as pseudosyntactical, Kuusela is in fact unwittingly embracing the substantial conception of nonsense.

Open Access This article is distributed under the terms of the Creative Commons Attribution 4.0 International License (http://creativecommons.org/licenses/by/4.0/), which permits unrestricted use, distribution, and reproduction in any medium, provided you give appropriate credit to the original author(s) and the source, provide a link to the Creative Commons license, and indicate if changes were made.

\section{References}

Anscombe, G. E. M. (1965). An introduction to Wittgenstein's Tractatus. New York: Harper Torchbooks. Bar-Elli, G. (1997). Frege's context principle. Philosophia, 25(1-4), 99-129.

Black, M. (1964). A companion to Wittgenstein's 'Tractatus. Cambridge: Cambridge University Press.

Bronzo, S. (2012). The Resolute Reading and Its Critics: An Introduction to the Literature. Wittgenstein Studien, 3(1), 45-80.

Conant, J. (1993). Kierkegaard, Wittgenstein, and Nonsense. In T. Cohen, P. Guyer, \& H. Putnam (Eds.), 1993. Pursuits of Reason-Essays in Honour of Stanley Cavell (pp. 195-224). Lubbock: Tech. University Press. 
Conant, J. (2000). Elucidation and nonsense in Frege and early Wittgenstein. In A. Crary \& R. Read (Eds.), 2000. The New Wittgenstein (pp. 174-217). London \& New York: Routledge.

Conant, J. (2002). The method of the Tractatus. In E. H. Reck (Ed.), 2002. From Frege to Wittgenstein: Perspectives on Early Analytic Philosophy (pp. 374-462). Oxford: Oxford University Press.

Conant, J., \& Bronzo, S. (2017). Resolute readings of the Tractatus. In H. J. Glock \& J. Hyman (Eds.), 2002. A Companion to Wittgenstein (pp. 175-194). Malden: Blackwell.

Conant, J., \& Diamond, C. (2004). On Reading the Tractatus resolutely. Reply to Meredith Williams and Peter Sullivan. In M. Kölbel \& B. Weiss (Eds.), 2004. Wittgenstein's Lasting Significance (pp. 46-99). London: Routledge.

Diamond, C. (1991a). Wittgenstein and Metaphysics. In C. Diamond (Ed.), 1991. The Realistic Spirit Wittgenstein, Philosophy, and the Mind (pp. 13-38). Cambridge: MIT Press.

Diamond, C. (1991b). Throwing away the ladder: How to Read the Tractatus. In C. Diamond (Ed.), 1991. The Realistic Spirit - Wittgenstein, Philosophy, and the Mind (pp. 179-204). Cambridge: MIT Press.

Diamond, C. (1991c). Riddles and Anselm's Riddle. In C. Diamond (Ed.), 1991. The Realistic Spirit Wittgenstein, Philosophy, and the Mind (pp. 267-289). Cambridge: MIT Press.

Diamond, C. (2000). Ethics, imagination and the Tractatus. In A. Crary \& R. Read (Eds.), 2000. The New Wittgenstein (pp. 149-173). London \& New York: Routledge.

Diamond, C. (2004). Saying and showing: An example from Anscombe. In B. Stocker (Ed.), 2004. PostAnalytic Tractatus (pp. 151-166). Burlington: Ashgate.

Diamond, C. (2005). Logical syntax in Wittgenstein's Tractatus. The Philosophical Quarterly, 55(218), 7889.

Diamond, C. (2011). The Tractatus and the limits of sense. In O. Kuusela \& M. McGinn (Eds.), 2011. The Oxford Handbook of Wittgenstein (pp. 240-275). Oxford \& New York: Oxford University Press.

Diamond, C. (2014). Wittgenstein and what can only be true. Nordic Wittgenstein Review, 3(2), 9-40.

Floyd, J. (2007). Wittgenstein and the inexpressible. In A. Crary (Ed.), 2007. Wittgenstein and the Moral Life: Essays in Honor of Cora Diamond (pp. 177-234). Cambridge: MIT Press.

Fogelin, R. (1976). Wittgenstein. London \& New York: Routledge.

Fogelin, R. (1983). Wittgenstein on Identity. Synthese, 56(2), 141-154.

Geach, P. T. (1976). Saying and showing in Frege and Wittgenstein. In J. Hintikka (Ed.), 1976. Essays on Wittgenstein in Honour of G. H von Wright. Acta Philosophica Fennica (Vol. 28, pp. 54-70). Amsterdam: Rodopi.

Goldfarb, W. (1997). Metaphysics and nonsense: On Cora Diamond's The Realistic Spirit. Journal of Philosophical Research, XXII, 57-73 22.

Goldfarb, W. (2011). Das Überwinden: Anti-metaphysical readings of the Tractatus. In R. Read \& M. A. Lavery (Eds.), 2011. Beyond the Tractatus Wars: The New Wittgenstein Debate (pp. 6-21). New York: Routledge.

Grover, D. (1972). Propositional Quantifiers. Journal of Philosophical Logic, 1(2), 111-136.

Hacker, P. M. S. (1975). Frege and Wittgenstein on elucidations. Mind New Series, 84(336), 601-609.

Hacker, P. M. S. (1986). Insight and illusion: Themes in the philosophy of Wittgenstein. Oxford: Clarendon Press.

Hacker, P. M. S. (1999). Naming, thinking and meaning in the Tractatus. Philosophical Investigations, 22(2), 119-135.

Hacker, P. M. S. (2000). Was he trying to whistle it? In A. Crary \& R. Read (Eds.), 2000. The New Wittgenstein (pp. 353-388). London \& New York: Routledge.

Hacker, P. M. S. (2003). Wittgenstein, Carnap and the new American Wittgensteinians. The Philosophical Quarterly, 51, No. 210, 1-23.

Helme, M. (1979). An elucidation of Tractatus 3.263. Southern Journal of Philosophy, 17(3), 323-324.

Hutchinson, P., \& Read, R. (2006). An elucidatory interpretation of Wittgenstein's Tractatus: A critique of Daniel D. Hutto's and Marie McGinn's reading of Tractatus 6.54. International Journal of Philosophical Studies, 14(1), 1-29.

Hutto, D. (2003). Wittgenstein and the end of philosophy. Basingstoke: Palgrave Macmillan.

Ishiguro, H. (1969). Use and reference of names. In P. Winch (Ed.), 1969. Studies in The Philosophy of Wittgenstein (pp. 20-50). London: Routledge.

Kenny, A. (1973). Wittgenstein. Malden: Blackwell.

Kremer, M. (2001). The purpose of Tractarian nonsense. Nous, 35(1), 39-73.

Kremer, M. (2002). Mathematics and meaning in the Tractatus. Philosophical Investigations, 25(3), $272-303$.

Kremer, M. (2007). The cardinal problem of philosophy. In A. Crary (Ed.), 2007. Wittgenstein and the Moral Life. Essays in Honor of Cora Diamond (pp. 143-176). Cambridge: The MIT Press. 
Kuusela, O. (2006). Nonsense and clarification in the Tractatus-Resolute and ineffability readings and the Tractatus' failure. In S. Pihlström (Ed.), 2006. Wittgenstein and the Method of Philosophy (Acta Philosophica Fennica, 80) (pp. 35-65). Societas Philosophica Fennica: Helsinki.

Kuusela, O. (2011). The dialectic of interpretations: Reading Wittgenstein's Tractatus. In R. Read \& M. A. Lavery (Eds.), 2011. Beyond the Tractatus Wars: The New Wittgenstein Debate (pp. 121-148). New York: Routledge.

Kuusela, O. (2012). Carnap and the Tractatus' Philosophy of Logic. Journal for the History of Analytical Philosophy, 1(3), 1-25.

Lampert, T., Säbel, M., 2016. Wittgenstein's Elimination of Identity for Quantifier-Free Logic. http://philsciarchive.pitt.edu/12974/. Accessed 3 January 2019.

Lugg, A. (2003). Wittgenstein's Tractatus: True thoughts and nonsensical propositions. Philosophical Investigations, 26(4), 332-347.

McGinn, M. (1999). Between metaphysics and nonsense: Elucidation in Wittgenstein's Tractatus. The Philosophical Quarterly, 49(197), 491-513.

McGinn, M. (2006). Elucidating the Tractatus: Wittgenstein's early philosophy of logic and language. Oxford: Clarendon Press.

McGuinness, B. (1981). The so-called realism of Wittgenstein's Tractatus. In I. Block (Ed.), 1981. Perspectives of the Philosophy of Wittgenstein (pp. 60-73). Cambridge: MIT Press.

Ostrow, M. (2004). Wittgenstein's Tractatus: A dialectical interpretation. Cambridge: Cambridge University Press.

Pears, D. (1988). The false prison: A study of the development of Wittgenstein's philosophy (Vol. I). Oxford: Clarendon Press.

Proops, I. (2001). The new Wittgenstein: A critique. European Journal of Philosophy, 9(3), 375-404.

Read, R., \& Deans, R. (2011). The possibility of a resolutely resolute Reading of the Tractatus. In R. Read \& M. Lavery (Eds.), Beyond the Tractatus wars (pp. 149-171). New York: Routledge.

Rhees, R. (1970). 'Ontology' and identity in the Tractatus. In R. Rhees (Ed.), 1970. Discussions of Wittgenstein (pp. 51-65). Bristol: Thoemmes Press.

Ricketts, T. (1996). Pictures, logic, and the limits of sense in Wittgenstein's Tractatus. In H. Sluga \& D. Stern (Eds.), 1996. The Cambridge Companion to Wittgenstein (pp. 59-99). Cambridge: Cambridge University Press.

Schlick, M. (1936). Meaning and verification. The Philosophical Review, 45(4), 339-369.

Stenius, E. (1960). Wittgenstein's Tractatus: A Critical Exposition of its Main Lines of Thought. Oxford: Blackwell.

Stern, D. (1995). Wittgenstein on Mind and Language. New York \& Oxford: Oxford University Press.

Sullivan, P. (2002). On trying to be resolute: A response to Kremer on the Tractatus. European Journal of Philosophy, 10(1), 43-78.

Waismann, F. (1979). Wittgenstein and the Vienna Circle. B. McGuinness (Ed.). Oxford: Blackwell.

White, R. (1977-1978). Wittgenstein on Identity. Proceedings of the Aristotelian Society, New Series, 78, $157-174$

White, R. (2011). Throwing the baby out with the ladder: On "therapeutic" readings of Wittgenstein's Tractatus. In R. Read \& M. A. Lavery (Eds.), 2011. Beyond the Tractatus Wars: The New Wittgenstein Debate (pp. 66-83). New York: Routledge.

Williams, M. (2004). Nonsense and cosmic exile: The austere reading of the Tractatus. In M. Kölbel \& B. Weiss (Eds.), 2004. Wittgenstein's Lasting Significance (pp. 1-27). London: Routledge.

Witherspoon, E. (2000). Carnap and Wittgenstein. In A. Crary \& R. Read (Eds.), 2000. The New Wittgenstein. London (pp. 315-349). New York: Routledge.

Wittgenstein, L. (1922). Tractatus Logico-Philosophicus. Transl. C. K. Ogden \& F. P. Ramsey. London: Routledge and Kegan Paul.

Wittgenstein, L. (1960). Preliminary Studies for the "Philosophical Investigations". Generally Known as "The Blue and Brown Books". New York: Harper Torchbooks.

Wittgenstein, L. (1961). Tractatus Logico-Philosophicus. Transl. D. F. Pears \& B. F. McGuinness. London: Routledge and Kegan Paul.

Wittgenstein, L. (1975). Philosophical Remarks. R. Rhees (Ed.). Oxford: Blackwell.

Publisher's Note Springer Nature remains neutral with regard to jurisdictional claims in published maps and institutional affiliations. 